\title{
Kimura's disease associated with IgA nephropathy: A case report
}

\author{
WEI ZHANG ${ }^{1}$, ANCHARAZ PREEATUM ${ }^{2}$ and CHUNYAN LIU ${ }^{1}$ \\ ${ }^{1}$ Department of Nephrology, Second Affiliated Hospital of Dalian Medical University, Dalian, Liaoning 116000, P.R. China; \\ ${ }^{2}$ Nephrology Unit, Internal Medicine Department, Flacq Regional Hospital, Central Flacq 40606, Mauritius
}

Received April 14, 2018; Accepted November 11, 2018

DOI: $10.3892 /$ etm.2018.7103

\begin{abstract}
Kimura's disease (KD) is a rare chronic inflammatory disorder of unknown etiology that manifests as painless subcutaneous lesions in the head and neck. It primarily affects young Asian males and is characterized by peripheral eosinophilia and elevated levels of serum Immunoglobulin (Ig) E. Histologically, a variety of renal lesions have been observed in patients with $\mathrm{KD}$, although $\operatorname{IgA}$ nephropathy is rarely reported. In the current study, a case of KD with an atypical manifestation accompanied with IgA nephropathy was reported in a middle-aged Chinese man. The subcutaneous lesion was located on the elbow of the patient. Although the recurrence rate of KD-associated nephrotic syndrome is high, the patient has not experienced relapse following 6 months of pulse treatment with methylprednisone and cyclophosphamide. In conclusion, methylprednisone combined with cyclophosphamide is effective in the treatment of KD-associated $\operatorname{Ig} \mathrm{A}$ nephropathy, and long-term administration of methylprednisone may achieve the effect of preventing KD recurrence.
\end{abstract}

\section{Introduction}

Kimura's disease (KD) was first described by Kimm and Szeto in 1937 (1) and the definitive histological description of the disease was subsequently reported by Kimura in 1948 (2). $\mathrm{KD}$ is a rare chronic inflammatory disorder that may lead to lymphadenopathy and subcutaneous lesions. It is characterized by plasma and tissue eosinophilia, raised levels of immunoglobulin ( $\mathrm{Ig}) \mathrm{E}$ and frequent complications of nephropathy (3). KD occurs mostly in Asian patients and has been considered limited to the Far East (4). It has previously been reported that $12-60 \%$ of patients with KD also exhibit coexisting renal disease (5). A number of histopathological renal lesions have been reported in this disease, particularly minimal change disease, membranous nephropathy and mesangioproliferative

Correspondence to: Dr Chunyan Liu, Department of Nephrology, Second Affiliated Hospital of Dalian Medical University, 467 Zhongshan Road, Dalian, Liaoning 116000, P.R. China

E-mail: liu_chunyan031@sina.com

Key words: Kimura's disease, immunoglobulin A nephropathy, methylprednisone disease (6). However, to the best of our knowledge, IgA nephropathy in patients with KD has rarely been reported. In the current study, a case of steroid-responsive IgA nephropathy associated with KD is reported.

\section{Case study}

A 45-year-old Chinese man was diagnosed with eosinophilic hyperplasia in May 2011. In June 2012, during a routine health examination, the patient's urine was analyzed and the results revealed the presence of grade $3+$ proteinuria. Approximately 6 months later, the patient went to another hospital (The First Affiliated Hospital Of Jinzhou Medical University (Jinzhou, China) and was diagnosed with proteinuria and hematuria. The patient was then admitted to Second Affiliated Hospital of Dalian Medical University (Dalian, China) due to gross hematuria and proteinuria in March 2017.

The patient also exhibited an oval-shaped subcutaneous swelling in his right elbow that had been present for 2 months. The swelling was $2.5 \mathrm{~cm}$ in diameter and presented a clear edge. In addition, the mobile swelling was neither tender nor indurated.

Upon physical examination, the blood pressure and heart rate of the patient were $135 / 80 \mathrm{mmHg}$ and 72 beats/min, respectively. The patient was also determined to be febrile.

The patient had no history of hypertension or diabetes. Laboratory tests revealed proteinuria 3+ (normal range, negative) and 2 consecutive $24 \mathrm{~h}$ urine analyses determined a protein content of 3.9 and $3.8 \mathrm{~g} / \mathrm{d}$, respectively. Normal values were provided previously (7). The urinary red blood cell (RBC) count of the patient was RBC:20/HP (normal range: 0-2/HP). Upon morphological examination (magnification, $x 40$ ), the shape of the urine RBCs were dysmorphic, indicating glomerular hematuria. A full blood count revealed: White blood cell count, $13.4 \times 10^{9} / 1$ (normal range: $3.50-9.50 \times 10^{9} / 1$ ); hemoglobin, $155 \mathrm{~g} / \mathrm{l}$ (normal range: 130-175 g/l); and eosinophilia, $3.53 \times 10^{9} / 1$ (normal range, $0.02-0.52 \times 10^{9} / 1$ ). Furthermore, a renal function test revealed the following: Urea, $6.10 \mathrm{mmol} / 1$ (normal range: 3.1-8.0 $\mathrm{mmol} / \mathrm{l}$ ) and serum creatinine, $115 \mu \mathrm{mol} / 1$ (normal range, 57-97 $\mu \mathrm{mol} / 1$ ). Serum total IgE levels were high, at 9,790.00 IU/ml (normal range 0-100 IU/ml). N Latex IgE mono kit (Siemens AG, Munich, Germany) was used for IgE assay. Hypersensitive c-reactive protein [analysed using an ELISA kit from Monobind, Inc. (Lake Forest, CA, USA); cat. no. 3125-000A] was $77.13 \mathrm{mg} / 1$ (normal range: $0-5 \mathrm{mg} / \mathrm{l}$ ) and the erythrocyte sedimentation 
rate (analysed using an automatic blood sedimentation dynamic analyzer) was $22.00 \mathrm{~mm} / \mathrm{h}$ (normal range: $0-15 \mathrm{~mm} / \mathrm{h}$ ). The hepatitis profile of the patient was normal. The results for antineutrophilic cytoplasmic antibody and antibodies associated with autoimmune hepatitis (including surface antibodies, E antibodies and core antibodies) were determined to be negative. Ultrasonography of the subcutaneous mass presented two swollen lymph nodes $(2.0$ and $1.3 \mathrm{~cm}$, respectively), and the hilus of these nodes indicated that these swollen lymph nodes had a blood supply. Bone marrow aspiration revealed eosinophilia hyperplasia only and excluded the possibility of other hematological diseases. A chest X-ray did not indicate any abnormalities. Ultrasonography results of the liver and renal artery were normal.

After informed consent was obtained from the patient, a renal biopsy was performed. The tissue was prefixed with ethanol:formaldehyde:PBS (7:3:1) at $4^{\circ} \mathrm{C}$ for $10 \mathrm{~min}$. Following prefixing, the tissues was fixed with Bouine stationary liquid (25 $\mathrm{ml} \mathrm{80 \%} \mathrm{ethanol} \mathrm{saturated} \mathrm{picric} \mathrm{acid} \mathrm{solution}+120 \mathrm{ml}$ formaldehyde $+220 \mathrm{ml}$ anhydrous ethanol $+60 \mathrm{ml}$ glacial acetic acid $+50 \mathrm{ml}$ water) at $4^{\circ} \mathrm{C}$ for $6 \mathrm{~h}$. Then the tissues were dehydrated at different ethanol concentrations $(75 \%$ ethanol, $85 \%$ ethanol, 95\% ethanol, absolute ethyl alcohol) for $20 \mathrm{~min}$ ateach concentration. The environmental friendly transparent dewaxing liquid was on the tissue for $30 \mathrm{~min}$, then specimens were embedded in paraffin at $65^{\circ} \mathrm{C}$ for $40 \mathrm{~min}$.

The specimens were embedded in paraffin and sliced to: i) 3- $\mu \mathrm{m}$ thickness and for immunohistochemistry and Congo red staining, ii) $2-\mu \mathrm{m}$ sections for hematoxylin and eosin (H\&E), periodic acid-Schiff and Masson staining, iii) $1.5-\mu \mathrm{m}$ sections for periodic acid silver methenamine (PASM) staining, and iv) $1-\mu \mathrm{m}$ sections for PASM + HE staining.

For H\&E staining, the nucleus was stained with hematoxylin at $25^{\circ} \mathrm{C}$ for $10 \mathrm{~min}$, then differentiated with $1 \%$ hydrochloric acid for $1 \mathrm{sec}$, and counterstained with Scott's bluing reagent ( $0.35 \mathrm{~g}$ sodium bicarbonate $+2 \mathrm{~g}$ magnesium sulfate $+100 \mathrm{ml}$ water) at $25^{\circ} \mathrm{C}$ for $10 \mathrm{sec}$. The cytoplasm was then stained with $5 \%$ eosin at $25^{\circ} \mathrm{C}$ for $5 \mathrm{~min}$.

A total of 34 glomeruli were detected via light microscopy (magnification, x100): Five glomeruli exhibited global sclerosis, one glomerulus exhibited segmental sclerosis, and two glomeruli presented with a cellular segmental crescent (Fig. 1). Renal tubules exhibited localized atrophy and tubule cells presented granular degeneration. A small quantity of protein casts were identified in the lumen and inflammatory cell infiltration was observed in the interstitium. Most infiltrating cells were eosinophils and several regions of the interstitium exhibited marked pathological changes to granulomas (Fig. 2). Glomerular basement membrane was normal. Immunofluorescence was performed as follows: Tissues were frozen on a glacial table and cut into $4-\mu \mathrm{m}$ frozen sections for immunofluorescence. Antibodies were diluted to working solution according to the appropriate dilution factor (IgA, $\operatorname{IgM}, \operatorname{IgG}, \mathrm{C} 3$ and $\mathrm{C} 4$ were diluted to 1:40, and $\mathrm{Clq}$ was diluted to 1:50). Tissues were incubated with the antibodies at $37^{\circ} \mathrm{C}$ for $30 \mathrm{~min}$. Tissues were then washed and differentiated with absolute ethyl alcohol. After drying, they were sealed with glycerin. Fluorescence microscopy was used to observe the tissues. It was revealed that several coarse granular deposits of $\operatorname{Ig} \mathrm{A}(3+)$ and $\mathrm{C} 3(2+)$ were present in several mesangial areas (Fig. 3).
Based on the results, the patient was diagnosed with $\lg \mathrm{A}$ nephropathy and interstitial nephritis.

The patient was administered methylprednisone pulse therapy (intravenous administration, $500 \mathrm{mg} / \mathrm{day}$ for 3 days), followed by oral $24 \mathrm{mg} /$ day methylprednisone and $0.8 \mathrm{mg} / \mathrm{kg} /$ day cyclophosphamide (the body weight of the patient was $72 \mathrm{~kg}$ ) for 4 weeks. Following 10 days of treatment, the swelling situated on the elbow disappeared while the peripheral eosinophil count returned to normal $\left(0.06 \times 10^{9} / 1\right)$. However, the levels of total serum $\operatorname{IgE}(9,030.00 \mathrm{IU} / \mathrm{ml})$ and proteinuria ( $2.8 \mathrm{~g} /$ day) did not show any marked reduction. Following 3 months, the level of serum creatinine dropped to $91 \mu \mathrm{mol} / 1$, while the level of $\operatorname{lgE}$ dropped to $5,653 \mathrm{IU} / \mathrm{ml}$. The patient was discharged in March 2017 following 20 days of hospitalization. During the follow-up visit conducted 6 months following discharge, $\operatorname{lgE}$ levels dropped to $2,810 \mathrm{IU} / \mathrm{ml}$ and $24 \mathrm{~h}$ proteinuria reduced to $0.4 \mathrm{~g}$ /day with no evidence of hematuria. In April 2018, the dose of methylprednisone was reduced to $8 \mathrm{mg} / \mathrm{day}$ and there was no evidence of relapse, although the patient is still being followed-up.

\section{Discussion}

KD was first described by Kimm and Szeto (1) in 1937 and the definitive histological description of the disease was reported by Kimura et al in 1948 (2). The majority of KD cases in Asian adults are associated with a protracted course $(4,8)$. KD is characterized by obvious peripheral blood eosinophilia and an elevated level of IgE, with subcutaneous swelling around the head and neck, particularly in the periauricular region (9). In addition, epitrochlear lymph nodes, inguinal lymph nodes and submandibular salivary glands are sites that are commonly affected (10). However, in cases of relapse, the disease may present over the entirety of the patient's body surface. Among previously reported cases, $1 \%$ of swellings were observed on the elbow, $>50 \%$ of patients exhibited a single lesion and $46.6 \%$ of patients exhibited multiple lesions (11). In the majority of cases, a definitive diagnosis can only be made following biopsy of the subcutaneous swelling (6). Although the patient in the current study refused to undergo a biopsy of subcutaneous swelling, his demographics and symptoms were typical of KD.

The association between KD and renal diseases including minimal change disease, membranous nephropathy and mesangioproliferative disease is well recognized (10). Minimal change disease and membranous nephropathy are the primary symptoms observed in patients from Asia, the majority of whom exhibit nephrotic syndromes (12). However, IgA nephropathy in patients with KD is rarely reported. To the best of our knowledge, the association between KD and IgA nephropathy was first reported in 1998 (13). Since then, only one more article (9) reported a case of KD associated IgA nephropathy. In each case, the patients also exhibited nephrotic syndrome. The renal histology results of the patient in the current study revealed granular and mesangial deposits of IgA and complement as detected by immunofluorescence. Therefore, the manifestation of nephritic syndrome in this patient strongly indicated the presence of $\operatorname{Ig}$ A nephropathy.

$\mathrm{KD}$ is an allergic and inflammatory disorder with unknown cause. It is believed that KD is caused by a type I hypersensitivity reaction or via a $\mathrm{T}$ cell-associated immune disorder (3). Ohta et al (14) demonstrated that Th2 cells (a subset of T helper 


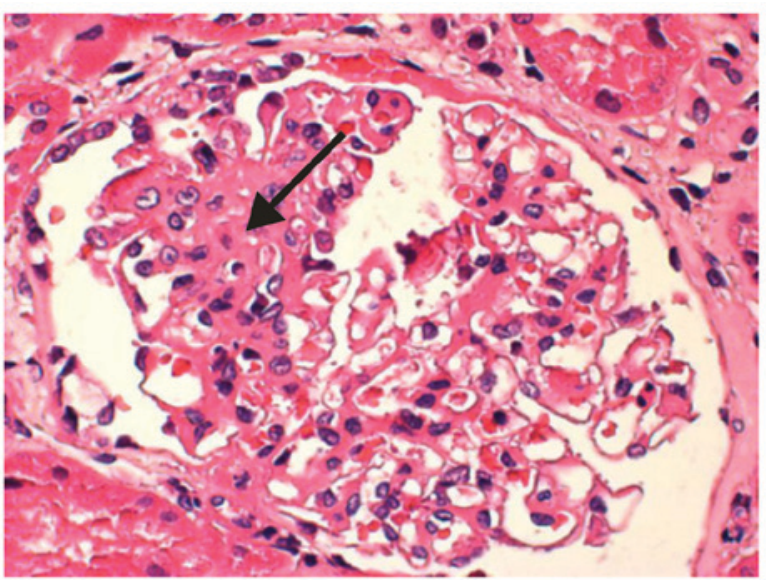

Figure 1. Hematoxylin and eosin staining of a glomerulus of the case exhibited marked mesangial proliferation and segmental sclerosis. Magnification, $\mathrm{x} 400$.

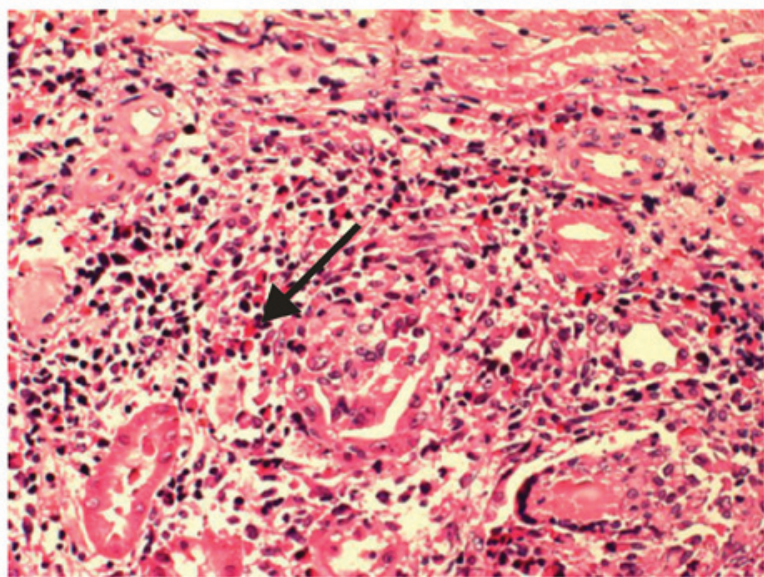

Figure 2. Interstitial granuloma pathological changes identified in the case study. Samples were stained with hematoxylin and eosin. Magnification, $\mathrm{x} 100$.

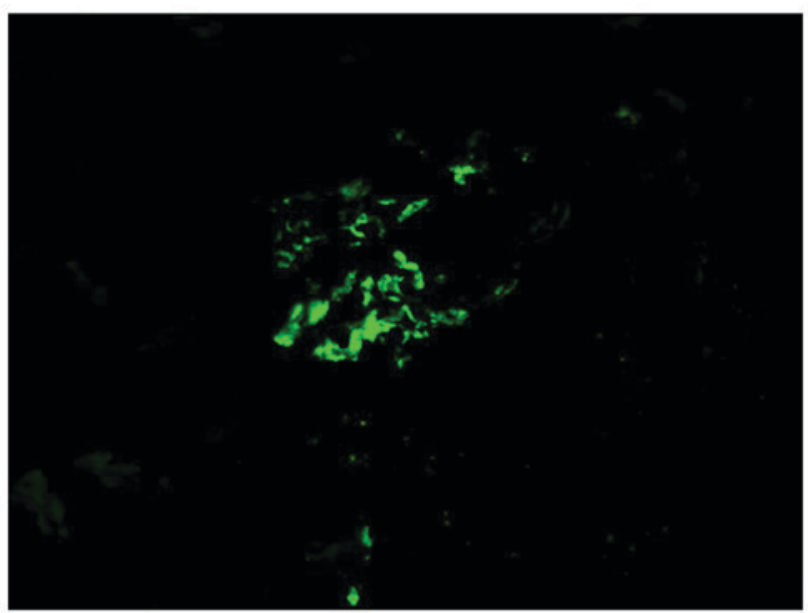

Figure 3. Immunofluorescence of coarse granular deposits of Immunoglobulin A. Magnification, $\mathrm{x} 400$.

cells), and Tc1 cells (a subset of $\mathrm{CD}^{+} \mathrm{T}$ cells), may contribute to the pathogenesis of KD. Furthermore, Yamazaki et al (15) demonstrated that an increased level of Th2 cells may serve important roles in the pathogenesis of KD by increasing the synthesis of certain Th2-type cytokines, including interleukin (IL)-4 and IL-5, which consequently increase eosinophilic infiltration and $\operatorname{IgE}$ synthesis. In addition, several previous studies have indicated that $\mathrm{T}$ cell-mediated tissue damage serves an important role in the immunopathogenesis of $\lg \mathrm{A}$ nephropathy (16). The involvement of various novel subsets of $\mathrm{T}$ cells in the immune responses of IgA nephropathy, including Th17 and Th1 cells, have also been confirmed (17). Previous studies have also determined that, compared with Iga nepropathy $(\operatorname{IgAN})$ patients without proteinuria, a higher percentage of Th22 cells were present in IgAN patients with proteinuria (18). In addition, Th22 cells were revealed to be involved in the immune responses of IgAN (19). During the patient's hospitalization the current study, he presented massive and relatively infrequent proteinuria, which we hypothesize may have been caused by an abnormality in $\mathrm{T}$ cell subsets. Taken together, the changes of $\mathrm{T}$ cells in patients with concurrent $\operatorname{Ig}$ A nephropathy and KD remain unclear and should be further investigated.

There is no consensus regarding the optimal treatment for KD. However, Surgical excision and systemic steroid therapy are the preferred treatments. Recurrence of $\mathrm{KD}$ is frequent after the cessation of treatment (20). A previous study has demonstrated that KD with renal recurrence is affected by sex, age and history of hypertension, and it usually presents a good prognosis (12). Nephrotic syndrome in patients with $\mathrm{KD}$ is usually treated with the oral administration of steroid hormones, such as methylprednisone, but patient response to the treatment varies (21). The occurrence of relapse was also revealed to depend on the results of renal histology $(22,23)$. In the case of the present study, the patient responded well to methylprednisone treatment and there was no recurrence of either elbow lesions or nephritis syndrome during follow-up.

A rare case of KD associated with $\operatorname{Ig}$ A nephropathy was described in the current study. The case also exhibited hematuresis and massive proteinuria. Short-term, the patient was successfully treated with methylprednisone combined with cyclophosphamide, while the prevention of KD relapse was achieved via the long-term administration of methylprednisone at a maintenance dose $(8 \mathrm{mg} / \mathrm{d})$. However, it cannot be concluded whether the long-term administration of methylprednisolone may be used as an effective strategy to prevent $\mathrm{KD}$ relapse and further studies are required for confirmation.

\section{Acknowledgments}

Not applicable.

\section{Funding}

The present study was supported by The technology Plan Projects for Liaoning Province, China (grant no. 20170540279).

\section{Availability of data and materials}

All data generated or analyzed during this study are included in this published article. 


\section{Authors' contributions}

WZ put forward the concepts of the present study, was responsible for designing and data analysis, and was a major contributor in writing the manuscript. CL provided the histological examination of the kidney, and contributed to the manuscript preparation and editing. AP contributed to the manuscript review and editing, and performed the pathological and immunohistochemical interpretation of the renal tissue.

\section{Ethics approval and consent to participate}

The present study was approved by the Ethics Committee of Second Affiliated Hospital of Dalian Medical University.

\section{Patient consent for publication}

Concent for publication has been provided.

\section{Competing interests}

The authors declare that they have no competing interests.

\section{References}

1. Kimm HT and Szeto C: Eosinophilic hyperplastic lymphogranuloma, comparison with Mikulicz's disease. Proc Chin Med Soc 1 329, 1937.

2. Kimura T, Yoshimura S and Ishikaura E: On the unusual granulation combined with hyperplastic changes of lymphatic tissue. Trans Soc Pathol Jpn 37: 179-180, 1948.

3. Rajpoot DK, Pahl M and Clark J: Nephrotic syndrome associated with Kimura disease. Pediatr Nephrol 14: 486-488, 2000.

4. Sorbello M, Laudini A, Morello G, Sidoti MT, Maugeri JG, Giaquinta A, Tallarita T, Corona D, Zerbo D, Cappellani A, et al: Anaesthesiological implications of Kimura's disease: A case report. J Med Case Rep 3: 7316, 2009.

5. Fouda MA, Gheith O, Refaie A, El-Saeed M, Bakr A, Wafa E, Abdelraheem $\mathrm{M}$ and Sobh M: Kimura Disease: A case report and review of the literature with a new management protocol. Int J Nephrol 2011: 673908, 2010.

6. Liu C, Hu W, Chen H, Tang Z, Zeng C, Liu Z and Li L: Clinical and pathological study of Kimura's disease with renal involvement. J Nephrol 21: 517-525, 2008.

7. Boege F: Urinary proteins. In: Clinical Laboratory Diagnostics. Thomas L (ed). 1st edition, TH-Books Verlagsgesellschaft, Frankfurt, pp 382-400, 1998.

8. Kung IT, Gibson JB and Bannatyne PM: Kimura's disease: A clinico-pathological study of 21 cases and its distinction from angiolymphoid hyperplasia with eosinophils. Pathology 16 39-44, 1984.
9. Hu YC, Wang R and Lv XA: Kimura disease associated with IgA nephropathy. Kaohsiung J Med Sci 30: 213-214, 2014.

10. Sun QF, Xu DZ, Pan SH, Ding JG, Xue ZQ, Miao CS, Cao GJ and Jin DJ: Kimura disease: Review of literature. Intern Med J 38: 668-674, 2008.

11. Adler BL, Krausz AE, Minuti A, Silverberg JI and Lev-Tov H: Epidemiology and treatment of angiolymphoid hyperplasia with eosinophilia (ALHE): A systematic review. J Am Acad Dermatol 74: 506-512, 2016.

12. Chen Y, Wang J, Xu F, Zeng C and Liu Z: Clinicopathological features and prognosis of Kimura's disease with renal involvement in Chinese patients. Clin Nephrol 85: 332-339, 2016.

13. Natov SN, Strom JA and Ucci A: Relapsing nephrotic syndrome in a patient with Kimura's disease and IgA glomerulonephritis. Nephrol Dial Transplant 13: 2358-2363, 1998.

14. Ohta N, Sakurai S, Yoshitake H and Aoyagi M: Analysis of Th1, $\mathrm{Th} 2, \mathrm{Tc} 1$ and Tc2 cells in patients with allergic rhinitis. Clin Exp All Rev 5: 68-71, 2005.

15. Yamazaki K, Kawashima H, Sato S, Tsunoda H, Yoshimura Y, Higuchi M, Hokibara S, Yamazaki T and Agematsu K: Increased CD45RO+ CD62L+ CD4+ T-cell subpopulation responsible for Th2 response in Kimura's disease. Hum Immunol 74: 1097-1102, 2013.

16. Peng Z, Tian J, Cui X, Xian W, Sun H, Li E, Geng L, Zhang L and Zhao P: Increased number of Th22 cells and correlation with Th17 cells in peripheral blood of patients with IgA nephropathy. Hum Immunol 74: 1586-1591, 2013.

17. Kurts C, Panzer U, Anders HJ and Rees AJ: The immune system and kidney disease: Basic concepts and clinical implications. Nat Rev Immunol 13: 738-753, 2013.

18. Duhen T, Geiger R, Jarrossay D, Lanzavecchia A and Sallusto F: Production of interleukin 22 but not interleukin 17 by a subset of human skin-homing memory T cells. Nat Immunol 10: 857-863, 2009.

19. Miyagaki T, Sugaya M, Suga H, Kamata M, Ohmatsu H, Fujita H, Asano Y, Tada Y, Kadono T and Sato S: IL-22, but not IL-17, dominant environment in cutaneous T-cell lymphoma. Clin Cancer Res 17: 7529-7538, 2011.

20. Liu XK, Ren J, Wang XH, Li XS, Zhang HP and Zeng K: Angiolymphoid hyperplasia with eosinophilia and Kimura's disease coexisting in the same patient: Evidence for a spectrum of disease. Australas J Dermatol 53: e47-e50, 2012.

21. Wang DY, Mao JH, Zhang Y, Gu WZ, Zhao SA, Chen YF and Liu AM: Kimura disease: A case report and review of the Chinese literature. Nephron Clin Pract 111: c55-c61, 2009.

22. Matsuda O, Makiguchi K, Ishibashi K, Chida Y, Ida T, Matsuda K, Tomita K, Marumo F and Hiruma M: Long-term effects of steroid treatment on nephrotic syndrome associated with Kimura's disease and a review of the literature. Clin Nephrol 37: 119-123, 1992.

23. Chartapisak W and Opastirakul S: Steroid-resistant nephrotic syndrome associated with Kimura's disease. Am J Nephrol 22: 381-384, 2002. 